\title{
Awareness on the Benefits of the Adoption of Dairy Vermicomposting Technology in Selected Cooperatives in Region 02
}

\author{
Nilo E. Padilla ${ }^{1, *}$, Joe Ann G. Payne ${ }^{2}$, Ralph John S. Lapastura ${ }^{2}$, Errol John A. Cadeliña ${ }^{2}$ \\ ${ }^{1}$ College of Agriculture, Isabela State University, Main Campus, Echague, 3309, Isabela, Philippines \\ ${ }^{2}$ Isabela State University, Main Campus, Echague, 3309, Isabela, Philippines
}

Received September 22, 2021; Revised October 20, 2021; Accepted November 29, 2021

\section{Cite This Paper in the following Citation Styles}

(a): [1] Nilo E. Padilla, Joe Ann G. Payne, Ralph John S. Lapastura, Errol John A. Cadeliña, "Awareness on the Benefits of the Adoption of Dairy Vermicomposting Technology in Selected Cooperatives in Region 02," Universal Journal of Agricultural Research, Vol. 9, No. 6, pp. 258 - 265, 2021. DOI: 10.13189/ujar.2021.090604.

(b): Nilo E. Padilla, Joe Ann G. Payne, Ralph John S. Lapastura, Errol John A. Cadeliña (2021). Awareness on the Benefits of the Adoption of Dairy Vermicomposting Technology in Selected Cooperatives in Region 02. Universal Journal of Agricultural Research, 9(6), 258 - 265. DOI: 10.13189/ujar.2021.090604.

Copyright $(2021$ by authors, all rights reserved. Authors agree that this article remains permanently open access under the terms of the Creative Commons Attribution License 4.0 International License

\begin{abstract}
There is a lack of information available on dairy vermicomposting technology in the Cagayan Valley Region, which has led to its non-adoption. The Department of Agriculture (DA) and other government organizations, on the other hand, have acknowledged and funded advocacy initiatives to raise awareness about the use of dairy manure in vermicomposting technology. As a result, the goal of this study was to determine the level of awareness, utilization, and adoption of vermicomposting technology using dairy manures, as well as to identify issues and constraints in the utilization and adoption of vermicomposting using dairy waste, and to suggest possible solutions. The Likert scale, frequency, percentage, and average mean were used to assess the data collected during the interview (FGD) and (KII). The average mean of the samples was used to calculate the levels of awareness, adoption, and utilization. According to the findings, Dairy MSMEs have an average level of awareness of 3.2, indicating that most of the respondents have moderately high awareness, while the level of adoption of Dairy MSMEs has an overall scale of 3.6, indicating that most of the respondents have a high level of adoption, resulting in a high level of utilization of vermicompost dairy manure. However, according to the distribution of the respondents' issues and concerns in the vermicomposting technology using dairy animal waste, the respondents' main concern was difficulty in integrating vermicomposting technology,
\end{abstract}

lack of technical know-how, added cost in the production process, costly and limited source of capital and insufficient technical and financial support. As a result, the study suggests that capacity building and access to loan windows are steps that should be taken to increase awareness and utilization of technology to strengthen respondents' knowledge, abilities, skills, behavior, and incomes in determining agricultural long-term strategy.

Keywords Adoption, Awareness, Dairy, Utilization, Vermicomposting

\section{Introduction}

With the advent of increasing interest in the adoption of sustainable and organic methods in the dairy industry, the importance of adopting vermiculture technology in the processes of dairy waste composting is beginning to be widely recognized. Kavita et al. [1] regarded vermicomposting as a clean, sustainable, and zero-waste approach to manage organic wastes but there are still some constraints in the popularization of vermicomposting. Instead of increasing research in the field of vermicomposting, they pointed that practical application of vermicomposting needs more attention. 
The use of vermicomposting dairy animal manure had been of increasing interest in the dairy industry; however, dairy farmers still face many challenges when it comes to managing animal waste manure. It was stated that it is necessary to guide farmers about vermicomposting and the appropriate use of vermicompost by organizing various training and extension activities [1].

In the study of Cristina et al. [2], it was reported that the effects of vermicomposting on plant-soil systems are not yet fully understood which resulted in the unawareness of the farmers on the significance of the technology in increasing crop production and its contribution to the mitigation of the emission of greenhouse gasses resulting to global warming. This is similar to the study of Kavita et al. [1] wherein they also pointed that one of the major constraints is the lack of awareness and proper knowledge regarding vermicomposting and the use of vermicompost.

Some of the potential benefits of vermicomposting technology are that it enhances plant growth, suppresses disease in plants, increases porosity and microbial activity in the soil, and improves water retention and aeration. It also benefits the environment by reducing the need for chemical fertilizers and decreasing the amount of waste going to landfills. Vermicompost production is trending up worldwide and it is finding increasing use especially in Western countries, Asia-Pacific, and Southeast Asia [3].

In addition, reduced use of water for irrigation, reduced pest attack, reduced termite attack, reduced weed growth; faster rate of seed germination and rapid seedlings growth and development; greater numbers of fruits per plant (in vegetable crops) and greater numbers of seeds per year (in cereal crops) are also some of the beneficial effects of the vermicompost usage in agricultural production [4].

Vermicomposting is the end product of earthworms' consumption of organic materials in the form of nutrient-rich "castings" and degraded bedding materials. Dairy producers are in an advantageous position to adopt and incorporate this vermicomposting technology into their manure handling systems due to the vast amounts of resources available from the farm such as manure and crop residues that can be used as bedding and feedstock for the worms [5].

However, despite the benefits associated with vermicomposting, the practical application and adoption of the technology using dairy manure are still at their early stage. In Cagayan Valley, for example, vermicomposting using refuse such as kitchen waste, garbage, and other waste materials has been a common practice but only a few or close to none are practicing or adopting vermicomposting using dairy animal manure in the region.

In the Province of Isabela, there is also a dearth of information on dairy vermicomposting technology which resulted in the non-adoption of the technology. However, the Department of Agriculture (DA) and the other government agencies have recognized and supported the advocacy campaigns on the awareness in the adoption of vermicomposting technology using dairy manure, hence this study.

In addition, this study would lead to the sustainable protection of the environment in support of the Ecological Waste Management (RA 9003) of the Philippines. As dairy farmers would engage or adopt this technology, they could increase their income through the increase of their yield production and this, in turn, could contribute to the mitigation of environmental pollution or global warming. Thus, the study aimed to determine the level of awareness, utilization, and adoption of vermicomposting technology using dairy manures.

\section{Objectives}

This study generally aims to review the awareness in the adoption and use of vermicompost technology using dairy animal waste in Region 02, Philippines.

Specifically, this study aims to achieve the following:

1. Determine the demographic profile of the respondents;

2. Assess the level of awareness of the dairy practitioners on the use of:

a To evaluate the level of utilization of the vermicompost in the production and farm operation of practitioners; and

b To evaluate the level of adoption of the vermicompost in the production and farm operation of practitioners;

3. Identify issues and constraints in the utilization and adoption of vermicomposting using dairy waste and recommend possible solutions;

4. Recommend intervention to intensify the awareness and utilization of vermicomposting technology.

\section{Review of Related Literature}

According to Nilo et al. [6] in their study, they pointed out the fact that the bulkiness of producing the nutrient content equivalent to inorganic fertilizer dampens the enthusiasm of the prospective vermin entrepreneurs to adapt to vermicomposting. However, if we are to consider and weigh the advantages or benefits derived from composting using dairy animal waste, it would mean to the contribution in mitigating environmental pollutions or gas emissions which is priceless in terms of health benefits and environmental safety of all the living in this polluted universe.

In one of the dairy congresses held at Tuguegarao City, Cagayan in 2018, it was pointed out that the same finding was also emphasized, reiterating the fact that the value or advantage of utilizing dairy animal waste would be priceless because this technology would recycle dairy manures that could cause environmental pollutions which 
would then lead to unprecedented calamities caused by global warming.

It was highly recommended in their study the adoption of vermicomposting using dairy animal waste as a material for vermicompost production that would contribute to the mitigation of environmental pollution, specifically in the gas emission of dairy animal wastes, and as a way of employment generation, thus increasing the income of the household farmers and improving the lives of the people in the community [6].

In addition, the study of Carlos [7] shows that in vermicomposting, the increasing trend in the number of vermin compost technology adaptors was popularized among local entrepreneurs for the reason that it is considered profitable and it maximizes the flow of materials within the farm level. He also stated that the process of utilizing the organic wastes within the farms leads to a more sustainable farming practice wherein nutrients are retained and returned to the soil through vermicompost application. Such practice would make the soil suitable for crop production and increase crop yield since the soil quality is improved.

\section{Research Methodology}

\section{A. Respondents and Location of the Study}

The study was conducted in Region 02, Philippines, wherein selected MSMEs, dairy cooperatives, and dairy practitioners were chosen as respondents. It was conducted from January to September 2021. Respondents of this study were the dairy farm practitioners and MSMEs in the selected municipalities in the Province of Isabela, particularly in the municipalities of Mallig, Roxas, and San Agustin, respectively.

\section{B. Data Gathering and Instrumentation}

Active dairy cooperatives, dairy farm practitioners, and dairy MSMEs in the region were identified as the target population in the conduct of the study. Request letters were then floated to the respective municipalities wherein the concerned respondents were identified. Proper communication and coordination procedures were done and followed with the help of their respective key officials. Three (3) municipalities in the region were identified to have the needed respondents and were purposively selected for the study, namely, the municipalities of Mallig, Roxas, and San Agustin, Isabela.

Primary data was gathered and obtained through questionnaires floated through virtual and face-to-face interviews, Focus Group Discussions (FGD), and Key Informant Interviews (KII). Purposive sampling was used to obtain respondents from the selected municipalities. Ten (10) respondents from the selected locations were then identified to have the qualities of the needed target population of the study. Data collected from the respondents include their socio-demographic profiles in terms of sex, age, educational attainment, years of operation, dairy farm animals, income, and family size.

A structured questionnaire was developed and used to obtain the necessary data needed for the study. It includes a set of questions relating to their socio-demographic profiles mentioned above in the first part, questions needed for evaluating their level of awareness, adoption, and utilization of the vermicomposting technology in its second part, and the issues and problems identified by the respondents in its last part.

Statistical tools used for data analysis include the Likert scale, frequency, percentages, and, average mean. Descriptive analysis was used to explain the socio-demographic characteristics of respondents in the study area.

\section{Data Analysis}

The gathered data from the interview were analyzed using the Likert scale, frequency, percentage, and average mean. Descriptive analysis was used to explain the socio-demographic characteristics of respondents in the study area. The level of awareness, adoption, and utilization were analyzed by computing the average mean of the samples. The following were the scale for the interpretation:

\begin{tabular}{|c|c|c|}
\hline $\begin{array}{c}\text { Likert Scale } \\
\text { Description }\end{array}$ & $\begin{array}{c}\text { Likert } \\
\text { Scale }\end{array}$ & Likert Scale Interval \\
\hline Low & 1 & $1.00-1.79$ \\
\hline Moderately Low & 2 & $1.80-2.59$ \\
\hline Moderately High & 3 & $2.60-3.39$ \\
\hline High & 4 & $3.40-4.19$ \\
\hline Very High & 5 & $4.20-5.00$ \\
\hline
\end{tabular}

*Five Point Likert Scale based on the study of Geraldine et al. [8].

Actual observations and documentation were also undertaken to validate the data.

\section{Results and Discussions}

\section{A. Socio-Demographic Profile of the Respondents}

The socio-demographic profile of the respondents in terms of sex, age, educational attainment, years of operation, dairy farm animals, income, and family size was determined in the conduct of the study and the results are as follows:

\section{a Socio-Demographic Profile of the Respondents in} terms of Sex

Table 1 shows the socio-demographic profile of the respondents in terms of their sex. As seen in the table, the majority $(70 \%)$ of the respondents were females. The results indicate that women could also be a part of the 
farming activities, contrary to the findings of Obi et al. [9], which reported a higher percentage of males $(67.2 \%)$ as the herdsmen/livestock farmers' structure compared to females $(32.8 \%)$ in Anambra State, Nigeria. It also contradicts the findings of John et al. [10] who reported a percentage of $59.6 \%$ of males engaging in dairy farming compared to a percentage of $40.4 \%$ females in Uganda.

Table 1. Socio-Demographic Profile of the Respondents in terms of Sex

\begin{tabular}{|c|c|c|}
\hline Sex & Frequency & Percentage \\
\hline Male & 3 & 30 \\
\hline Female & 7 & 70 \\
\hline Total & 10 & 100 \\
\hline
\end{tabular}

b Socio-Demographic Profile of the Respondents in terms of Age

Table 2. Socio-Demographic Profile of the Respondents in terms of Age

\begin{tabular}{|c|c|c|}
\hline Age & Frequency & Percentage \\
\hline $48-50$ & 4 & 40 \\
\hline $51-53$ & 1 & 10 \\
\hline 54 and above & 5 & 50 \\
\hline Total & 10 & 100 \\
\hline Average Age & & \\
\hline
\end{tabular}

Table 2 indicates the socio-demographic profile of the respondents in terms of their age. Base on the gathered results, most of the respondents belong to ages 54 and above. It indicates that the vermicomposting technologies were mostly adopted by said age group. These results, however, were contrary to the findings of John et al. [10] in their study, wherein the largest percentage of the age group that adopts the said technology was within the age bracket of 30-40 years $(46.54 \%)$.

c Socio-Demographic Profile of the Respondents in terms of Educational Attainment

Table 3. Socio-Demographic Profile of the Respondents in terms of Educational Attainment

\begin{tabular}{|c|c|c|}
\hline $\begin{array}{c}\text { Educational } \\
\text { Attainment }\end{array}$ & Frequency & Percentage \\
\hline Elementary & 1 & 10 \\
\hline High School & 7 & 70 \\
\hline College & 2 & 20 \\
\hline Total & 10 & 100 \\
\hline
\end{tabular}

Table 3 shows the socio-demographic profile of the respondents in terms of their educational attainment. The results of the interview shown in the table indicate that most of the respondents were high school graduates, $20 \%$ of them were college graduates and $10 \%$ of them were elementary graduates. The results indicate that majority of the practitioners were high school graduates, which is similar to the findings of Khayali et al. [11], wherein 20 percent of the respondents in their study were educated up to high school level, followed by middle school and primary school level.

\section{d Socio-Demographic Profile of the Respondents in terms of Years of Operation}

Table 4. Socio-Demographic Profile of the Respondents in terms of Years of Operation

\begin{tabular}{|c|c|c|}
\hline Years of Operation & Frequency & Percentage \\
\hline $1-5$ years & 7 & 70 \\
\hline 6-10 years & 2 & 20 \\
\hline 11 years above & 1 & 10 \\
\hline Total & 10 & 100 \\
\hline
\end{tabular}

Table 4 indicates the socio-demographic profile of the respondents in terms of their years of operation. It is shown in the table that in the conducted interview, the majority of the respondents were engaged for 1-5 years of using the vermicomposting technology, $20 \%$ of them engaged for about 6-10 years of operation and, $10 \%$ of them engaged for more than 11 years of the technology operation. Contrary to the findings of Uddin et al. [12], the majority (40.18\%) of their respondents had about 10 years of experience, and the least number of farmers $(14.73 \%)$ had more than 20 years of rearing experience.

\section{e Socio-Demographic Profile of the Respondents in terms of Dairy Farm Animals}

Table 5. Socio-Demographic Profile of the Respondents in terms of Dairy Farm Animals

\begin{tabular}{|c|c|c|}
\hline Dairy Farm Animal & Frequency & Percentage \\
\hline Carabao & 6 & 60 \\
\hline Cattle & 4 & 40 \\
\hline Total & 10 & 100 \\
\hline
\end{tabular}

The table above shows the socio-demographic profile of the respondents in terms of their dairy farm animals. Based on the gathered results shown in the table, in terms of dairy farm animals, Table 5 indicates that the majority of the respondents were engaged in raising carabao. This indicates that dairy carabao raisers dominate the dairy cattle raisers.

\section{$f \quad$ Socio-Demographic Profile of the Respondents in terms of Income}

Table 6 indicates the socio-demographic profile of the respondents in terms of their income. The results show that the majority of the respondents have a marginal average income of Php 1,000.00 to 17,500.00. This result contradicts the findings of Verma et al. [13], wherein they reported that the majority of their respondents $(46.50 \%)$ were in the medium-income followed, by low income $(27.00 \%)$ and, high income $(26.50 \%)$, respectively. 
Table 6. Socio-Demographic Profile of the Respondents in terms of Income

\begin{tabular}{|c|c|c|}
\hline Income Range & Frequency & Percentage \\
\hline $\begin{array}{c}\mathrm{P} 1,000.00- \\
\mathrm{P} 17,500.00\end{array}$ & 6 & 60 \\
\hline $\begin{array}{c}\mathrm{P} 17,501.00-\mathrm{P} \\
34,001.00\end{array}$ & 3 & 30 \\
\hline $\mathrm{P} 34,000.00$ and above & 1 & 10 \\
\hline Total & 10 & 100 \\
\hline
\end{tabular}

$g \quad$ Socio-Demographic Profile of the Respondents in terms of Family Size

Table 7. Socio-Demographic Profile of the Respondents in terms of Family Size

\begin{tabular}{|c|c|c|}
\hline Family Size & Frequency & Percentage \\
\hline $1-2$ & 2 & 20 \\
\hline $3-4$ & 4 & 40 \\
\hline $5-6$ & 4 & 40 \\
\hline Total & 10 & 100 \\
\hline
\end{tabular}

Table 7 shows the socio-demographic profile of the respondents in terms of their family size. As seen in the table, the results indicate that $40 \%$ of the respondents have family sizes of 3-4 and 5-6 members, respectively. This result coincides with the findings of Satyanarayan et al. [14] wherein they revealed that the majority (68.33\%) of their respondents had big size families followed by the small size of families (31.67\%). The family size of dairy animal owners had a negative but non-significant relationship with the adoption of improved dairy husbandry practices.

\section{B. Level of Awareness, Adoption, and Utilization of the Dairy Practitioners}

The level of awareness, adoption and utilization of the vermicomposting technology of the dairy practitioners were evaluated in the conduct of the study and the results are as follows:

\section{a Level of Awareness of the Dairy MSMEs on the Use of Vermicompost Dairy Manure in Farming}

Table 8 shows the level of awareness of the dairy MSMEs on the use of vermicompost dairy manure in farming. Based on the results shown in the table, it indicates that the level of awareness of the Dairy MSMEs has an average level of awareness equivalent to 3.2, which means that most of them have moderately high awareness. This means that the respondents were generally aware of the use of vermicomposting technology using dairy manure in farming. In the study of Jeffrey et al. [15], it was pointed out that many vermin raisers were beginners who adopted vermiculture for less than one year, as revealed by 15 out of 47 respondents. Next in rank was 1-2 years with a total of 11 or $23.40 \%$, followed by $4-5$ years with $17.02 \%$, then $2-3$ years and 5 years and above with 6 or $12.77 \%$ and lastly, 3-4 years with 1 or $2.13 \%$.
Their data revealed that $75 \%$ of the respondents had a medium level of knowledge and had a strong favorable attitude $(74.17 \%)$, while the $69.17 \%$ of the respondents had a medium practice level towards vermiculture technology.

Table 8. Level of Awareness of the Dairy MSMEs on the Use of Vermicompost Dairy Manure in Farming

\begin{tabular}{|c|c|c|}
\hline Scale & Frequency & Percentage \\
\hline 1 - Low & 1 & 10 \\
\hline 2- Moderately Low & 1 & 10 \\
\hline 3 - Moderately High & 4 & 40 \\
\hline 4 - High & 3 & 30 \\
\hline 5 - Very High & 1 & 10 \\
\hline Total & 10 & \\
\hline Overall Scale & 3.2 & Moderately High \\
\hline
\end{tabular}

$b$ Level of Adoption of Vermicompost Dairy Manure in Farming

Table 9. Level of Adoption of Vermicompost Dairy Manure in Farming

\begin{tabular}{|c|c|c|}
\hline Scale & Frequency & Percentage \\
\hline 1 - Low & 2 & 20 \\
\hline 2- Moderately Low & 1 & 10 \\
\hline 3- Moderately High & 1 & 10 \\
\hline 4 - High & 1 & 10 \\
\hline 5 - Very High & 5 & 50 \\
\hline Total & 10 & \\
\hline Overall scale & 3.6 & High \\
\hline
\end{tabular}

Table 9 indicates the level of adoption of vermicompost dairy manure in farming. The results show that the level of the adoption of the Dairy MSMEs has an overall scale equivalent to 3.6, which means that most of the respondents have a high level of adoption. Swetha et al. [16], in their study, revealed that about $56.67 \%$ established the vermicompost as an enterprise, and $41.18 \%$ of respondents who adopted belonged to high adoption level. All their respondents fully adopted the recommended practices concerning pit construction with recommended size and method of watering. While $96.67 \%$ considered recommended points for selection of the site and sequential method of filling the pit as per the procedure, $95.00 \%$ fully adopted the method of harvesting and $93.33 \%$ adopted the practice of several worms to be released $/ \mathrm{m}^{2}$.

\section{c Level of Utilization of Vermicompost Dairy Manure in Farming}

Table 10 shows the level of utilization of vermicompost dairy manure in farming. As seen in the table, the results indicate that the level of utilization of the vermicompost dairy manure in farming has an overall scale equivalent to 3.7, which means that most of the respondents have a high 
level of utilization. Liyue et al. [17] stated that the utilization of vermicompost in agricultural productivity increase has been largely demonstrated.

Table 10. Level of Utilization of Vermicompost Dairy Manure in Farming

\begin{tabular}{|c|c|c|}
\hline Scale & Frequency & Percentage (\%) \\
\hline 1- Low & & \\
\hline 2- Moderately Low & 2 & 20 \\
\hline 3- Moderately High & 2 & 20 \\
\hline 4- High & 3 & 30 \\
\hline 5- Very High & 3 & 30 \\
\hline Total & 10 & 100 \\
\hline Overall Scale & 3.7 & High \\
\hline
\end{tabular}

\section{Issues and Constraints in the Utilization and Adoption of Vermicomposting using Dairy Waste}

The issues and constraints in the utilization and adoption of vermicomposting using dairy waste were identified in the conduct of the study. The graph shows the distribution of the respondents' issues and concerns in the vermicomposting technology using dairy animal waste.

As seen in figure 1, it was identified that the respondents' main concern $(30 \%)$ was its added costs in the production process in the dairy farm in adopting the vermicomposting technology. The costly technology and limited sources of capital for acquisition and implementation of the vermicomposting technology in the farm were also stated by $20 \%$ of the respondents. This may be due to the higher cost of adopting organic fertilizer, like using dairy animal waste, than synthetic fertilizer which serves as an obstacle for farmers to adopt organic farming [1]

Findings also found that $20 \%$ of the respondents identified concerns on the lack of technical know-how about vermicompost technology. This result is similar to the study of Kavita et al. [1] wherein they stated that one of the major constraints is the lack of awareness and proper knowledge regarding vermicomposting and the use of vermicompost. It is necessary to guide farmers about vermicomposting and the appropriate use of vermicompost by organizing various training and extension activities.

In addition, $20 \%$ of the respondents stated that it is difficult for them to integrate the vermicompost technology using dairy animal manure in their activities on the farm. This may be due to their lack of proper knowledge in using the technology. It is then necessary to guide farmers about vermicomposting and the appropriate use of vermicompost by organizing various training and extension activities [1].

Furthermore, insufficient technical and financial support from the government for green dairy technologies was also identified by the remaining $10 \%$ of respondents. It was stated by Kavita et al. [1] that the mass application of vermicompost is not achieved due to the failure of policy implementation related to vermicompost technology.

Based on this data, it can be interpreted that there are still concerns that need to be further addressed in the adoption of the dairy vermicomposting technology. Future research should focus on these issues. This will help in increasing the awareness of farmers in adopting dairy vermicomposting technology.

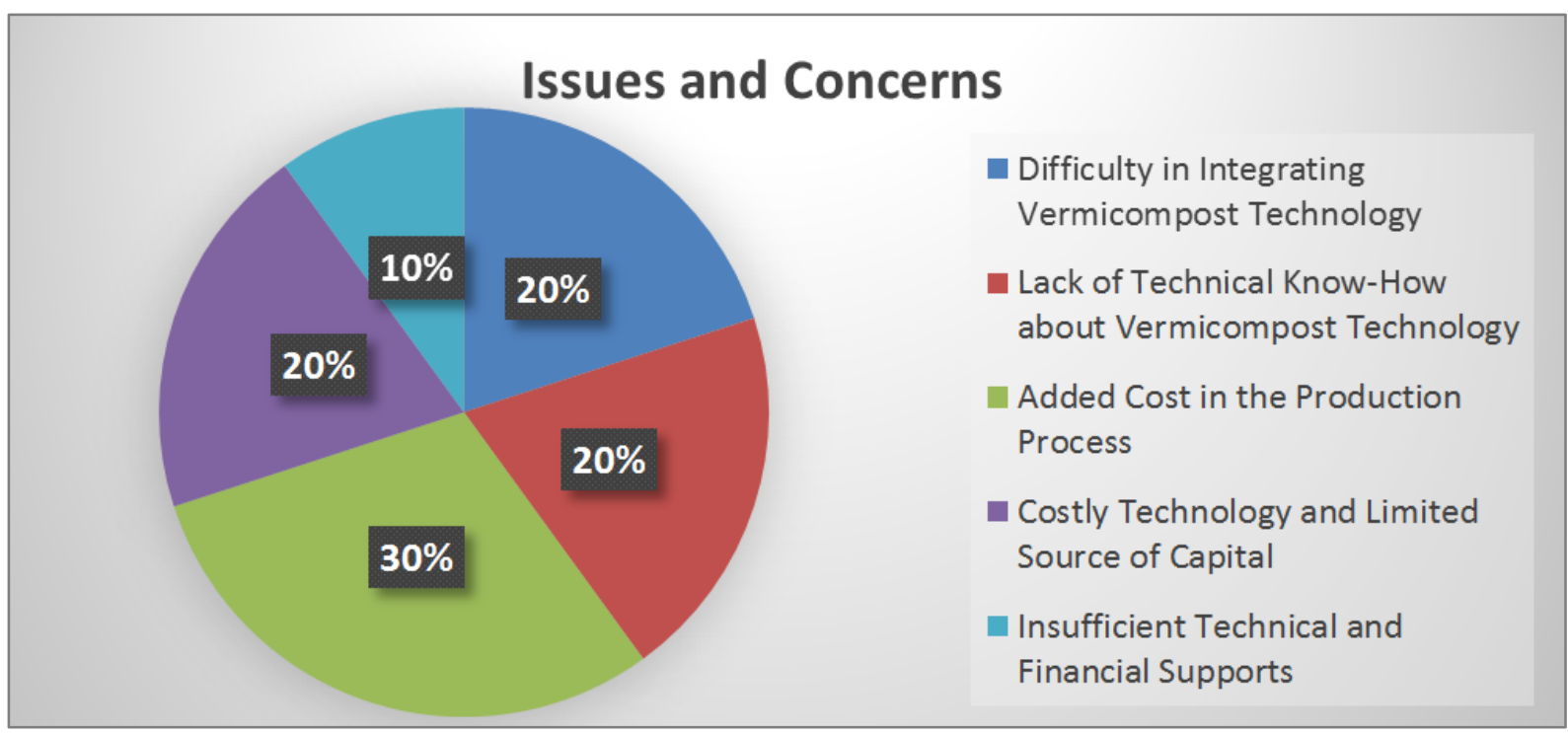

Figure 1. Distribution of the Respondents' Issues and Concerns 


\section{Interventions to Intensify the Awareness and Utilization of Vermicomposting Technology}

This is based on the identified issues and concerns raised by respondents using vermicomposting technology with dairy waste. As a result, this intervention suggests that the following steps be taken to increase awareness and utilization of the aforementioned technology:

- Capacity Building - Strengthening the respondents' knowledge, abilities, skills, and behavior, as well as improving institutional structures and processes, so that the respondent can meet its mission and goals in terms of technical know-how in utilizing the vermicomposting technology. It is the ability to take advantage of the potential for further growth, allowing the respondent to advance even further and face any challenges that may arise along the way.

- Access to Loan Windows - Credit availability is a key aspect in determining agriculture's future orientation. Poor people in emerging nations face a credit crunch that prevents them from investing and growing their income. Thus, access to loan windows is an antidote to rural poverty alleviation and it encourages the adoption of the respondents to new technologies like vermicomposting that will increase farmers' income and thus alleviate their poverty. Although the vermicomposting technology is still in its infant stage, it will still benefit the respondents to know that access to loan windows is available for them as they continue to adopt and utilize the said technology.

\section{Conclusion and Recommendations}

The level of awareness, utilization, and adoption of vermicomposting technology using dairy manures in Region 02 was reviewed and evaluated in this study. According to the findings, Dairy MSMEs have an average level of awareness of 3.2, indicating that most of them have moderately high awareness, while the level of adoption of Dairy MSMEs has an overall scale of 3.6, indicating that most of the respondents have a high level of adoption, resulting in a high level of utilization of vermicompost dairy manure.

The socio-demographic profile of the dairy practitioners was also determined in terms of sex, age, educational attainment, years of operation, dairy farm animal, income, and family size. Furthermore, several issues and constraints in the utilization and adoption of vermicomposting using dairy waste were identified. According to the distribution of the respondents' issues and concerns in the vermicomposting technology using dairy animal waste, the respondents' main concern was difficulty in integrating vermicomposting technology, lack of technical know-how, added cost in the production process, costly and limited source of capital and insufficient technical and financial support.

Possible solutions and interventions were recommended to intensify the awareness and utilization of the vermicomposting technology. As a result, the study suggests that capacity building and access to loan windows are steps that should be taken to increase awareness and utilization of technology to strengthen respondents' knowledge, abilities, skills, behavior, and incomes in determining agricultural long-term strategy.

Vermicomposting using dairy manure is still considered in its infant stage in Region 02. Although it has started a long time ago by practicing other methods of vermicomposting, dairy farmers did not gain momentum in the adoption of the technology using dairy animal waste due to the influences of several issues and concerns in adopting the said technology.

As stated in the findings of this study, the dairy practitioners in the Cagayan Valley still need to further their knowledge in the practical application of adopting the vermicomposting technology using dairy manure. It is necessary to guide the dairy farmers about the appropriate use of dairy vermicomposting to increase their awareness of the benefits of integrating the said technology. Governmental support from the appropriate agencies also needs to further their support, both in technical and financial, to the dairy practitioners for them to be able to integrate the vermicompost technology.

Future in-depth research should focus on the various challenges, issues, and problems faced by the dairy practitioners identified in this study. This will help in increasing the awareness of farmers in adopting dairy vermicomposting technology.

\section{Acknowledgement}

This study is in collaboration with the Commission on Higher Education (CHED) - Kto12 DARE TO Grant Program titled "Greening Dairy Rural Industry Value Chain towards Economic and Environmental Sustainability in Cagayan Valley, R02" and implemented by the Isabela State University. The authors wish to thank the Commission on Higher Education and the Isabela State University for their financial support and technical assistance which led to the realization of this study.

\section{REFERENCES}

[1] Kavita S., Vinod K.G., "Vermicomposting of Waste: A Zero-Waste Approach for Waste Management," Sustainable Resource Recovery and Zero Waste Approaches, pp. 133-164, 2019. DOI: 10.1016/B978-0-44 4-64200-4.00010-4

[2] Cristina L., Jorge D., "The Use of Vermicompost in 
Sustainable Agriculture. Impact on Plant Growth and Soil Fertility," Nova Science Publishers, Inc., 2011.

[3] Salman Z., "Benefits of Vermicompost," Bioenergy Consult, https://www.bioenergyconsult.com/tag/benefits-o f-vermicompost/ (accessed: Sept. 7, 2021)

[4] Margit O., "Review: Vermicompost, its importance, and Benefit in Agriculture," Journal of Agricultural Science, vol. 30, no. 2, pp. 93-98, 2019. DOI: 10.15159/jas.19.19

[5] UMass, "Vermicomposting on Dairy Farms," UMass Extension Crops, Dairy, Livestock, and Equine Program, https://ag.umass.edu/crops-dairy-livestock-equine/fact-she ets/vermicomposting-on-dairy-farms (accessed: Oct. 19, 2021)

[6] Nilo P., Diosdado C., Visitacion S., "Organic Fertilizer Value Chain Opportunities and Challenges in Cagayan Valley, Philippines," Journal of Advanced Agricultural Technologies, vol. 4, no. 2, pp. 128-133, 2017. DOI: 10.18178/joaat.4.2.128-133

[7] Carlos T., "Business Plan on Vermicomposting" https://cupdf.com/document/business-plan-on-vermicompo sting.html (accessed: Sept. 7, 2021)

[8] Geraldine P., Daniel J., “Occupants Conservation Attitudes on Energy Consumption: The Case in Isabela State University in Cabagan, Isabela," ResearchGate, KnE Social Sciences, vol. 3, no. 6, p. 270, 2018. DOI: $10.18502 /$ kss.v3i6.2386

[9] Obi F.O., Boniface O.U., Joel N., "Agricultural Waste Concept, Generation, Utilization, and Management," Nigerian Journal of Technology, vol. 35, no. 4, pp. 957-964, 2016. DOI: $10.4314 /$ njt.v35i4.34

[10] John O.A., Sunday C.O., Rahamon A.M.A., Sunday K.O., "Socio-Demographic Structure and Constraints of Smallholder Dairy Farmers in Oyo State, Nigeria," International Journal of Livestock Research, vol. 9, no. 7,

\section{DOI: $10.5455 /$ ijlr.20190325063829}

[11] N.K. Khyalia, M.P. Sagar, Jitendra P., "Impact of Dairy Cooperative Society on the Overall Status of Member Dairy Farmers," Agricultural Rural Development, vol. 2, pp. 20-23, 2015.

[12] Uddin, M.N., Uddin, M.B., Al Mamun, M., Hassan, M.M., Khan, M.M.H, "Small Scale Dairy Farming for Livelihoods of Rural Farmers: Constraint and Prospect in Bangladesh," Journal of Animal Science Advances, vol. 2, no. 6, pp. 543-550, 2012.

[13] Verma, A.P., Panchbhai, G.J., Siddiqui, M.F., Sawant, M.N. A.P., "Correlation Analysis of Socio-Demographic Profile of Dairy Farmers with Knowledge and Adoption of Animal Husbandry Practices," International Journal of Current Microbiology and Applied Sciences, vol. 6, no. 3., pp. 1918-1925, 2017. DOI: 10.20546/ijcmas.2017.603.218

[14] Satyanarayan K., Vankayala J., "A Study on Knowledge and Adoption Behavior of Livestock Farmers," Indian Journal of Agricultural Research, vol. 44, no. 2, pp. 100-106, 2010.

[15] Jeffrey V., Renante P., Moises T., "Perceptions of Vermi Raisers on Different Vermicomposting Practices Adopted in Zamboanga Del Sur, Philippines," International Journal of Science and Management Studies, vol. 2, no. 4, pp. 45-54, 2019.

[16] Swetha M., Naaiik B., Kumar V., Rajkumar B., Vijayalakshmi D., Bhavyamanjari M., "Adoption of Vermicompost Technology," Indian Journal of Entomology, vol. 82, no. 1, pp. 32-35, 2020. DOI: $10.5958 / 0974-8172.2020 .00007 .3$

[17] Liyue G., Guanglei W., Caihong L., Wenjing L., Xiaofan Y., Da C., Gaomin J, "Vermicomposting with Maize Increases Agricultural Benefits by 304\%," Agronomy for Sustainable Development, vol. 35, pp. 1149-1155, 2015. 